BMJ Open

Diabetes

Research

\& Care

\title{
Social determinants of health impacting adherence to diabetic retinopathy examinations
}

\author{
Cindy X Cai (D) , ${ }^{1}$ Yixuan Li, ${ }^{2}$ Scott L Zeger, ${ }^{3}$ Melissa L McCarthy ${ }^{2}$
}

To cite: Cai CX, Li Y, Zeger SL, et al. Social determinants of health impacting adherence to diabetic retinopathy examinations. BMJ Open Diab Res Care 2021;9:e002374. doi:10.1136/ bmjdrc-2021-002374

\section{- Additional supplemental material is published online only. To view, please visit the journal online (http://dx.doi. org/10.1136/bmjdrc-2021- 002374).}

Received 8 May 2021 Accepted 11 September 2021

Check for updates

(C) Author(s) (or their employer(s)) 2021. Re-use permitted under CC BY-NC. No commercial re-use. See rights and permissions. Published by BMJ.

${ }^{1}$ Wilmer Eye Institute, Johns Hopkins Hospital, Baltimore, Maryland, USA

${ }^{2}$ Department of Health Policy and Management, Milken Institute School of Public Health, George Washington University, Washington, DC, USA ${ }^{3}$ Department of Biostatistics, Bloomberg School of Public Health, Johns Hopkins University, Baltimore, Maryland, USA

Correspondence to Dr Cindy X Cai; ccai6@jhmi.edu

\section{ABSTRACT}

Introduction This study evaluates the association of multidimensional social determinants of health $(\mathrm{SDOH})$ with non-adherence to diabetic retinopathy examinations. Research design and methods This was a post-hoc subgroup analysis of adults with diabetes in a prospective cohort study of enrollees in the Washington, DC Medicaid program. At study enrollment, participants were given a comprehensive SDoH survey based on the WHO SDoH model. Adherence to recommended dilated diabetic retinopathy examinations, as determined by qualifying Current Procedural Terminology codes in the insurance claims, was defined as having at least one eye examination in the 2-year period following study enrollment.

Results Of the 8943 participants enrolled in the prospective study, 1492 (64\% female, 91\% non-Hispanic Black) were included in this post-hoc subgroup analysis. $47.7 \%(n=712)$ were adherent to the recommended biennial diabetic eye examinations. Not having a regular provider (eg, a primary care physician) and having poor housing conditions (eg, overcrowded, inadequate heating) were associated with decreased odds of adherence to diabetic eye examinations $(0.45(95 \% \mathrm{Cl} 0.31$ to 0.64$)$ and 0.70 (95\% Cl 0.53 to 0.94$)$, respectively) in the multivariate logistic regression analysis controlling for age, sex, race/ ethnicity, overall health status using the Chronic Disability Payment System, diabetes severity using the Diabetes Complications Severity Index, history of eye disease, and history of diabetic eye disease treatment.

Conclusions A multidimensional evaluation of $\mathrm{SDoH}$ revealed barriers that impact adherence to diabetic retinopathy examinations. Having poor housing conditions and not having a regular provider were associated with poor adherence. A brief SDoH assessment could be incorporated into routine clinical care to identify social risks and connect patients with the necessary resources to improve adherence to diabetic retinopathy examinations.

\section{INTRODUCTION}

Diabetic retinopathy is a major cause of visual impairment and blindness among adults in the USA, with a rising prevalence paralleling the increase in diabetes mellitus. ${ }^{1-3}$ Vision loss from diabetic retinopathy is preventable but necessitates regular screening and follow-up. ${ }^{4}$ Early detection and prompt intervention for the vision-threatening complications of diabetic retinopathy, including diabetic

\section{Significance of this study}

What is already known about this subject?

- Vision loss from diabetes can be prevented through early screening and regular follow-up for timely intervention and prompt treatment.

- Adherence to diabetic retinopathy examinations is impacted by social determinants of health.

What are the new findings?

- A multidimensional evaluation of social determinants of health identified novel associations with poor adherence to diabetic retinopathy examinations, having poor housing and not having a regular provider.

How might these results change the focus of research or clinical practice?

- Evaluating and addressing social determinants of health should be built into routine clinical diabetic retinopathy examinations to promote adherence.

macular edema and proliferative diabetic retinopathy, with intravitreal injections of anti-vascular endothelial growth factor agents or panretinal photocoagulation can result in more than $90 \%$ reduction in blindness. ${ }^{5}$ Despite national recommendations for annual or biennial dilated comprehensive diabetic retinopathy examinations, patient adherence to guidelines is only $15 \%-77 \% .^{6-8}$ Diabetic retinopathy examination rates are particularly low in vulnerable populations, including racial and ethnic minority groups and low-income adults, highlighting the health disparities that exist in diabetic retinopathy care. ${ }^{9-11}$

Evidence suggests that social determinants of health $(\mathrm{SDoH})$, the conditions in which people live, work, and play, have a tremendous impact on health and healthcare behaviors and underlie much of the observed health disparities. ${ }^{12} \mathrm{SDoH}$ is a multidimensional construct in which structural determinants (eg, socioeconomic status) operate through intermediary determinants (material circumstances, behavioral factors, and 
psychosocial factors) to shape health. ${ }^{12}{ }^{13}$ Understanding the SDoH that are critical to adherence to diabetic retinopathy examinations requires a comprehensive evaluation of multidimensional determinants. ${ }^{12}$ To date, there has been limited literature evaluating multidimensional SDoH relevant to diabetic retinopathy care. Existing studies of adherence to diabetic retinopathy examination guidelines have largely focused on socioeconomic status and access to healthcare. ${ }^{11}{ }^{15-17}$ There has been little attention to other important intermediary determinants, for example housing conditions and stability, in the context of adherence to diabetic retinopathy examinations. ${ }^{18} 19$ Only by evaluating multiple determinants simultaneously can the most impactful SDoH be determined. Understanding the most impactful SDoH can help guide future interventions to address $\mathrm{SDoH}$ and promote adherence. The objective of this study is to identify the most important determinants, out of a broad multidimensional evaluation of $\mathrm{SDoH}$, of adherence to diabetic retinopathy examinations in a sample of Medicaid beneficiaries in Washington, DC.

\section{METHODS}

Subjects

This was a post-hoc subgroup analysis of a prospective cohort study. The details of the prospective study design are described in detail elsewhere. ${ }^{20}$ In brief, Englishspeaking adult patients between 18 and 64 years of age insured by the Washington, DC Medicaid program were screened for eligibility from September 2017 to December 2018 at an emergency department or a clinic affiliated with one of two Washington, DC hospitals. English-speaking patients were enrolled since the survey was only available in English. Patients were excluded if they were unable or unwilling to provide consent or were concurrently enrolled in Medicare. The upper age limit of 64 years was chosen since enrollment in Medicare starts at the age of 65 . Research assistants completed a faceto-face 35-item SDoH questionnaire with each eligible participant at study enrollment. All participants' adjudicated Medicaid claims for 2 years before and 2 years after the study enrollment date were obtained and linked to the $\mathrm{SDoH}$ questionnaire.

For the present post-hoc study, the subsample of adult patients with type 2 diabetes mellitus diagnosed in the 2-year pre-study enrollment claims was analyzed. Patients were identified based on the International Classification of Diseases version 10 codes associated with inpatient or outpatient encounters and outpatient medications for type 2 diabetes (online supplemental table 1). Patients with type 1 diabetes mellitus were excluded from this post-hoc analysis because this population has different screening recommendations ${ }^{421}$ (online supplemental table 1). Patients with type 1 diabetes are recommended to obtain screening diabetic eye examinations 5 years after onset of diabetes, while recommended screening is at the time of diagnosis for patients with type 2 diabetes.
With only 2 years of pre-study enrollment claims and unknown date of diabetes diagnosis, we cannot verify that a patient with type 1 diabetes meets the recommendation for a diabetic eye examination. As such, the decision was made to exclude patients with type 1 diabetes.

\section{SDoH questionnaire}

The SDoH questionnaire was based on the World Health Organization (WHO) conceptual framework for social determinants. ${ }^{12}$ It used validated survey questions and took about 10 min to complete. ${ }^{20}$ Structural determinants included questions on the highest level of education achieved and employment status (working full-time, working part-time, or not working). Intermediary determinants included questions on material circumstances, behavioral factors, and psychosocial factors. Material circumstances included food security, financial strain (trouble paying phone bill, utilities, or rent/ mortgage), internet access at home, access to a car for medical appointments, and housing. We evaluated type of housing (house, apartment, single room, mobile home, shelter, hotel or motel, or homeless), duration of housing, housing conditions (which include overcrowded, inadequate heating, rodents or bug infested, plumbing problems/water leaks, front door does not lock, mold, broken/boarded up windows, or other), and housing stability. Behavioral factors included questions on having a regular doctor (eg, for annual physicals), smoking status, alcohol consumption, illicit drug use, and exercise. Finally, psychosocial factors included social support and loneliness, marital status, domestic partner violence, and history of incarceration.

\section{Outcome}

The 2-year post-study enrollment claims were examined for adherence to the recommended annual or biennial diabetic eye examinations. ${ }^{4}$ Eye examinations were based on the presence of qualifying Current Procedural Terminology $\operatorname{codes}^{67}$ (online supplemental table 1). The primary outcome was adherence to biennial diabetic eye examinations, defined as the presence of at least one eye examination in the 2-year post-study enrollment period. The secondary outcome used for sensitivity analysis was adherence to annual diabetic eye examinations, defined as the presence of at least two eye examinations separated by at least 10 months in the 2-year post-study enrollment period.

\section{Statistical analysis}

All SDoH variables were treated as categorical variables and dichotomized for analysis. ${ }^{20}$ Missing $\mathrm{SDoH}$ elements were minimal and ranged $0 \%-0.6 \%$ for each of the 35-item questions. We used multiple imputation by chained equations and assumed missing at random to impute the missing dichotomous values for each item. Pearson's $\chi^{2}$ test was used to compare categorical variables and analysis of variance for continuous variables. Logistic regression analysis was used to measure the strength of 
association for each of the SDoH elements, controlling for baseline age (divided into categories of 18-34, 35-54, and $55+$ for ease of comparison), sex, self-reported race/ ethnicity (non-Hispanic black, non-Hispanic white, Latino or Hispanic, other), Chronic Disability Payment System (CDPS) score, history of eye disease, history of diabetic eye disease treatment, and Diabetes Complications Severity Index (DCSI).

The CDPS score, history of eye disease, history of diabetic eye disease treatment, and DCSI were derived from the 2-year pre-study enrollment claims data. The CDPS score is a risk adjustment measure developed for the Medicaid population representing the overall health of the beneficiary in which higher scores represent sicker patients. ${ }^{22}$ Diagnoses and pharmaceutical codes are mapped to major disease categories and the total CDPS score is calculated as the weighted sum of each category. ${ }^{2022}$ History of eye disease is a binary variable in which presence of any eye condition not including diabetic retinopathy (eg, cataracts, glaucoma) in the 2-year pre-study enrollment claims data was noted (online supplemental table 1). History of diabetic eye disease treatment is a binary variable in which the presence of any intravitreal injections, focal laser, or panretinal photocoagulation to treat the complications of diabetic macular edema or proliferative diabetic retinopathy was noted (online supplemental table 1). The DCSI is a scoring system for diabetes complications based on the presence and severity of complications in seven body systems. ${ }^{23}$ The DCSI has a possible range of $0-13$, with a higher score connoting more diabetic complications involving seven possible categories (retinopathy, nephropathy, neuropathy, cerebrovascular, cardiovascular, peripheral vascular disease, and metabolic). These covariates were chosen because they have been associated with adherence to diabetic retinopathy examinations in other studies. ${ }^{6711}$

A final multivariate logistic regression model was constructed in a forward stepwise fashion by sequentially adding to the baseline model SDoH regressors that were statistically significant in $\chi^{2}$ test. Statistical significance was set at $\mathrm{p} \leq 0.05$. We conducted a post-hoc power analysis comparing the difference in the prevalence of $\mathrm{SDoH}$ factors by adherence given our sample size. We had adequate power (ie, $80 \%$ or greater) to detect a difference of $>5 \%$ in the adherence rate if the $\mathrm{SDoH}$ factor was relatively rare (ie, $\leq 10 \%$ ) and could detect a difference of $>7 \%$ in adherence rate if the $\mathrm{SDoH}$ factor was more prevalent (ie, $\geq 20 \%$ ). All statistical analyses were performed in SAS/STAT software (V.9.4 of the SAS system for Windows).

\section{RESULTS}

During the 16-month enrollment period, 17719 patients were screened and 12346 were identified as eligible for the original prospective study. Among the eligible patients, 3403 were unable or unwilling to participate in the study $(79 \%)$ or had completed their medical visit before the research assistant was able to approach them $(21 \%)$. Of the 8943 participants ultimately enrolled in the prospective study, 1492 had type 2 diabetes and were included in this post-hoc analysis. We excluded 27 participants who had type 1 diabetes. The mean age was 49 years (range 18-68). Majority of the participants were women (64\% female, $n=955)$ and $91 \%(n=1363)$ self-identified as non-Hispanic black. The average CDPS score was 8.7 (95\% CI 8.33 to 9.08$)$. Of the participants, $45 \% \quad(n=678)$ had a history of eye disease in the 2-year pre-study enrollment period and $2.4 \% \quad(n=36)$ had a history of diabetic eye disease treatment. The average DCSI score was 2.43 (95\% CI 2.33 to 2.53) (table 1).

Adherence was met by $47.7 \% \quad(n=712)$ of participants who had at least one eye examination in the 2-year poststudy enrollment period. Only $17 \% \quad(n=254)$ of participants met the more stringent definition of adherence with at least two examinations during this period. Table 2 shows the distribution of adherence to diabetic eye examinations by each individual SDoH factor. In logistic

Table 1 Distribution of sociodemographic characteristics of the population with diabetes by eye examination status

\begin{tabular}{lllc}
\hline & \multicolumn{3}{l}{ Eye examination during 2-year poststudy enrollment period } \\
\cline { 2 - 4 } Characteristics & Yes $(\mathbf{n}=\mathbf{7 1 2})$ & No $(\mathbf{n}=\mathbf{7 8 0})$ & P value \\
\hline Mean age (SD) & $50.13(0.95)$ & $48.35(10.66)$ & 0.0008 \\
\hline Female sex, $\mathrm{n}(\%)$ & $534(68)$ & $421(59)$ & 0.0002 \\
\hline Non-Hispanic black, $\mathrm{n}(\%)$ & $710(91)$ & $653(92)$ & 0.6368 \\
\hline Chronic Disability Payment System score, $\mathrm{n}(\%)$ & & & 0.005 \\
\hline First tertile (healthiest) & $252(32)$ & $245(34)$ & \\
\hline Second tertile & $289(37)$ & $209(29)$ & \\
\hline Third tertile (sickest) & $239(31)$ & $258(36)$ & 0.1816 \\
\hline DCSI score (SD) & $2.51(2.37)$ & $2.34(2.35)$ & $<0.0001$ \\
\hline History of eye disease, $\mathrm{n}(\%)$ & $448(57)$ & $230(32)$ & 0.0019 \\
\hline History of diabetic eye disease treatment, $\mathrm{n}(\%)$ & $28(4)$ & $8(1)$ & \\
\hline
\end{tabular}

DCSI, Diabetes Complications Severity Index; SD, Standard Deviation. 
Table 2 Distribution of structural and intermediary social determinants of health by diabetic eye examination status

\begin{tabular}{|c|c|c|c|}
\hline \multirow[b]{2}{*}{ Social determinant of health } & \multicolumn{3}{|c|}{ Eye examination during 2-year poststudy enrollment perioc } \\
\hline & $\begin{array}{l}\text { Yes (n=712) } \\
n(\%)\end{array}$ & $\begin{array}{l}\text { No }(n=780) \\
n(\%)\end{array}$ & $P$ value \\
\hline \multicolumn{4}{|l|}{ Structural determinants } \\
\hline $\begin{array}{l}\text { No high school degree/general educational } \\
\text { development certification or higher }\end{array}$ & $188(24)$ & $173(24)$ & 0.9299 \\
\hline Not working (part-time or full-time) & $509(65)$ & $464(65)$ & 0.9716 \\
\hline \multicolumn{4}{|l|}{ Intermediary: social } \\
\hline Single/separated/divorced/widowed & $650(83)$ & $615(86)$ & 0.1021 \\
\hline Living with children & $290(37)$ & $262(37)$ & 0.8788 \\
\hline History of abusive relationship & $245(31)$ & $231(32)$ & 0.6688 \\
\hline History of being in jail or prison & $246(32)$ & $278(39)$ & 0.0024 \\
\hline Feeling lonely (good bit/most/all of the time) & $153(20)$ & $155(22)$ & 0.3045 \\
\hline \multicolumn{4}{|l|}{ Intermediary: health behaviors } \\
\hline No regular doctor for health needs & $53(7)$ & $105(15)$ & $<0.0001$ \\
\hline Current smoker (daily or less than daily) & $301(39)$ & $309(43)$ & 0.0591 \\
\hline $\begin{array}{l}\text { Drinks alcohol (male }>14 \text { drinks/week; female }>7 \\
\text { drinks/week) }\end{array}$ & $26(3)$ & $32(4)$ & 0.2465 \\
\hline Illicit drugs (not including marijuana) & $24(3)$ & $41(6)$ & 0.0113 \\
\hline Less physical activity & $344(44)$ & $331(46)$ & 0.355 \\
\hline \multicolumn{4}{|l|}{ Intermediary: financial strain } \\
\hline Trouble paying phone bill & $614(79)$ & $557(78)$ & 0.8189 \\
\hline Trouble paying utilities & $547(70)$ & $512(72)$ & 0.4488 \\
\hline \multirow{2}{*}{ Trouble paying rent/mortgage } & $591(76)$ & $550(77)$ & 0.5014 \\
\hline & \multicolumn{3}{|c|}{ Eye examination during 2-year poststudy enrollment perioc } \\
\hline Social determinant of health & $\begin{array}{l}\text { Yes }(n=712) \\
n(\%)\end{array}$ & $\begin{array}{l}\text { No }(n=780) \\
n(\%)\end{array}$ & $P$ value \\
\hline \multicolumn{4}{|l|}{ Intermediary: material resources } \\
\hline No access to car for medical appointments & $424(54)$ & $398(56)$ & 0.5503 \\
\hline Limited to no internet access & $112(14)$ & $112(16)$ & 0.4589 \\
\hline Food insecure & $282(36)$ & $244(34)$ & 0.4467 \\
\hline \multicolumn{4}{|l|}{ Intermediary: housing } \\
\hline Does not live in a house or apartment & $77(10)$ & $77(11)$ & 0.5499 \\
\hline Poor housing conditions & $115(15)$ & $134(19)$ & 0.0349 \\
\hline Housing instability & $190(24)$ & $198(28)$ & 0.1292 \\
\hline Living in same residence for $<1$ year & $101(13)$ & $92(13)$ & 0.9874 \\
\hline
\end{tabular}

regression modeling of each individual SDoH controlling for age, gender, race/ethnicity, CDPS score, history of eye disease, history of diabetic eye disease treatment, and DCSI score, only two SDoH factors significantly predicted adherence to diabetic eye examinations. Participants who reported that they did not have a regular doctor that they saw had $55 \%$ lower odds of being adherent to diabetic eye examinations (OR $0.45,95 \%$ CI 0.31 to 0.64 , $\mathrm{p}<0.05)$. Participants who reported having poor housing conditions (eg, overcrowded, inadequate heating) had $30 \%$ lower odds of adherence to diabetic eye examinations (OR $0.70,95 \%$ CI 0.53 to $0.94, p<0.05)$. In the final multivariate model, which included SDoH regressors that were significant in the $\chi^{2}$ test, not having a regular provider and having poor housing conditions continued to predict non-adherence to diabetic eye examinations (table 3).

Sensitivity analyses were performed using the more stringent definition of adherence with two eye examinations in the 2-year poststudy enrollment period and the results were qualitatively similar. In the final multivariate model, not having a regular provider again decreased the odds of adherence to diabetic eye examinations (OR $0.47,95 \%$ CI 0.24 to $0.83, \mathrm{p}<0.05)$. Living with children 
Table 3 Adjusted OR of having an eye examination in the 2-year poststudy enrollment period

\begin{tabular}{|c|c|c|}
\hline Characteristics & OR (95\% Cl) & $P$ value \\
\hline \multicolumn{3}{|l|}{ Age $\left(18-34^{\star}\right)$} \\
\hline $35-54$ & 1.58 (1.11 to 2.26$)$ & 0.0119 \\
\hline $55+$ & 1.68 (1.15 to 2.46$)$ & 0.0073 \\
\hline Female sex (male) & 1.54 (1.22 to 1.93$)$ & 0.0002 \\
\hline Non-Hispanic black (no) & 0.88 (0.60 to 1.30$)$ & 0.5273 \\
\hline \multicolumn{3}{|l|}{ CDPS (first tertile: healthiest) } \\
\hline Second tertile & 1.12 (0.86 to 1.48$)$ & 0.4016 \\
\hline Third tertile (sickest) & 0.69 (0.50 to 0.96$)$ & 0.0274 \\
\hline DCSI score & 1.01 (0.95 to 1.07$)$ & 0.7566 \\
\hline History of eye disease (no) & 2.79 (2.23 to 3.49$)$ & $<0.0001$ \\
\hline $\begin{array}{l}\text { History of diabetic eye } \\
\text { disease treatment (no) }\end{array}$ & 2.19 (1.00 to 5.35$)$ & 0.0642 \\
\hline $\begin{array}{l}\text { No regular doctor for health } \\
\text { needs (has) }\end{array}$ & 0.45 (0.31 to 0.64$)$ & $<0.0001$ \\
\hline Poor housing conditions (no & 0.70 (0.53 to 0.9 & 0.0176 \\
\hline
\end{tabular}

${ }^{*}$ Reference group for each variable is detailed in parentheses. CDPS, Chronic Disability Payment System; DCSI, Diabetes Complications Severity Index.

was associated with decreased odds of examinations (OR $0.71,95 \%$ CI 0.51 to $0.99, \mathrm{p}<0.05)$, while poor housing condition was not associated.

\section{DISCUSSION}

This indepth examination of multidimensional SDoH in a low-income, non-Hispanic black Medicaid population highlights the important role that $\mathrm{SDoH}$ play in impacting adherence to diabetic retinopathy examinations. Even after eliminating cost as a barrier, one of the most commonly reported reasons for not receiving eye care, ${ }^{10}{ }^{24}$ several $\mathrm{SDoH}$ factors emerged as significant predictors of adherence. Our two main findings are that (1) regular healthcare providers, such as primary care doctors, family care doctors, or general practitioners, have an important role in promoting adherence to diabetic retinopathy examinations, and that (2) patients who have poor housing conditions can have decreased adherence to diabetic retinopathy examinations. These associations suggest possible targets for hospital or community-based interventions to promote diabetic retinopathy examinations.

The rates of diabetic retinopathy examinations in our population, $48 \%$ using the biennial definition and $17 \%$ using the annual definition, are largely consistent with other reported rates in the literature, which range from $15 \%$ to $77 \% .^{6-8}$ It is as high as $70 \%-77 \%$ by national surveys and integrated healthcare systems. ${ }^{24-26}$ In the Medicare population, adherence ranges from $25 \%$ to $60 \%$ when defined as one eye examination in a 15-month period. $^{6} 79$ In a predominantly low-income African American population with diabetes in Alabama, diabetic retinopathy examination screening rate was about $30 \% .{ }^{27}$ In an urban Hispanic population with diabetes in Los Angeles, 35\% had eye examinations within the previous 12 months. ${ }^{28}$ In an urban Medicaid population in the mid-Atlantic, similar to our study, the adherence rate was $46 \%$ for annual examinations. The lowest rates of adherence were reported by Benoit and colleagues ${ }^{8}$ using the IBM MarketScan Research Database. The authors report only $15 \%$ of patients with type 2 diabetes without diabetic retinopathy and $51 \%$ with diabetic retinopathy met the annual or biennial eye examination recommendation, compared with $42 \%$ and $58 \%$, respectively, in our population. It is difficult to compare rates of eye examinations between studies due to differences in the underlying population and varying definitions of 'adherence'. What is clear, however, is that the rate of diabetic retinopathy examinations for most populations, including ours, continue to fall short of the Healthy People 2030 goal of $67.6 \% .^{29}$ The Healthy People initiative is a set of sciencebased objectives released by the US Department of Health and Human Services designed to guide national health promotion by setting targets to monitor and motivate progress. ${ }^{30}$

Evaluating and addressing $\mathrm{SDoH}$ are potential means to improve adherence to diabetic retinopathy examinations. Our study found decreased adherence in those without regular healthcare providers, who had poor housing conditions, and were living with children. Regular healthcare providers, including primary care physicians, play a central role in coordination of care and promoting adherence to diabetes guidelines, including diabetic retinopathy examinations. ${ }^{31}$ Not surprisingly, patients who responded that they "have a regular doctor that [they] see" had increased odds of being adherent to diabetic retinopathy examinations, using both the primary outcome and in the sensitivity analyses. Strategies aimed at decreasing barriers in the referral process to eye care and improving communication between ophthalmologists and primary care physicians are effective in increasing eye examination rates. ${ }^{32}{ }^{33}$ Future hospitalbased interventions could focus on further improving this connection.

Having poor housing conditions has not been previously associated with adherence to diabetic eye examinations. Multiple mechanisms could explain this association. Poor housing conditions could be a general indicator of poverty. Living in overcrowded conditions is a precursor to homelessness and can make it difficult to attend preventive services and perform self-care. ${ }^{13} 1819$ The physical aspects of where people live, or the built environment, can influence physical activity, walkability, and transportation to access healthcare. ${ }^{34} 35$ The association of poor housing conditions with adherence to diabetic eye examinations adds to the expanding literature on the critical role of housing in health. It is unknown why poor housing condition was not associated with adherence in sensitivity analyses. In the univariate model, poor housing conditions had a borderline association (OR 0.72, 95\% 
CI 0.47 to $1.10, \mathrm{p}=0.13$ ) with decreased adherence to eye examinations that was not statistically significant. It could be that poor housing is an important SDoH but not the most important one, or that there could be fluctuations in the data due to sample size. Lastly, living with children also showed decreased odds of eye examinations in the sensitivity analyses. The cohort living with children in general were 7.5 years younger than those who were not. One possible explanation is that this cohort had added caregiving responsibilities that interfered with healthy behaviors and follow-up. ${ }^{36}$

It is unknown why the other $\mathrm{SDoH}$ were not associated with adherence to diabetic retinopathy examinations. For example, not having a high school degree has been previously associated with increased non-adherence to diabetic retinopathy examination, but not in our study. ${ }^{37}$ It could be that in the context of multiple SDoH, structural determinants including education are not as significant as intermediary determinants. Another possibility could be a combination of the sample size and the number of patients with social adversities. In this cohort, $34 \%$ of the population had very few social risks and were largely employed; only $12 \%$ had the most social risks and were unemployed, and the majority of patients fell somewhere in between. ${ }^{20}$ Financial strain can impact adherence to diabetic retinopathy examination but our study did not find this association. ${ }^{24}$ It could also be that having insurance supersedes other measures of financial strain by eliminating the financial barrier to diabetic retinopathy examinations. We also found a lower adherence among younger male patients with type 2 diabetes, which is consistent with other studies. ${ }^{25} 37$ Other studies have found an association of race/ethnicity with adherence to diabetic retinopathy examinations, while our study did not. ${ }^{113738}$ A key difference is that our study was in a largely homogenous population of $91 \%$ black persons; thus, there was not enough heterogeneity to delineate the role of race/ethnicity. In addition, race/ethnicity is often used as a surrogate for socioeconomic status, whereas this is a relatively homogenous group of low-income adults.

Although most experts agree that $\mathrm{SDoH}$ underlie health outcomes, there is little consensus on how they should be assessed and incorporated into routine clinical care. There is a wide variety of published tools and guidelines that emphasize different aspects of SDoH. ${ }^{39-42}$ There is no consensus on a specific set of factors defining $\mathrm{SDoH}$ and there is a lack of standardized nomenclature across the field, but what is clear is that $\mathrm{SDoH}$ is a multidimensional construct. ${ }^{12} 134344$ Existing literature examining $\mathrm{SDoH}$ in diabetic retinopathy care has predominantly focused on socioeconomic status and access to healthcare and has not assessed other dimensions of SDoH. By evaluating multiple determinants, even in our brief 10 min survey, we were able to highlight novel associations between $\mathrm{SDoH}$ and adherence to diabetic retinopathy examinations. An evaluation of multidimensional SDoH could be incorporated into routine clinical diabetic retinopathy examinations. For example, initial screening questions could include elements such as not having a primary care physician or poor housing conditions that subsequently lead into further questions and evaluations. Ultimately, addressing these $\mathrm{SDoH}$ and connecting patients to needed services could lead to improved patient adherence to eye examinations. More work is needed to identify the precise list of multidimensional SDoH that are relevant for adherence to diabetic retinopathy examinations and the best methodology to screen for them.

This study has a number of limitations. The results of this study are not generalizable as the cohort is not a representative sample of Medicaid beneficiaries. We enrolled a group of individuals who were already seeking treatment. The Washington, DC Medicaid program has an expansive eligibility criteria and covered services; thus, the enrollees in the Washington, DC Medicaid program might not be reflective of populations enrolled in other state Medicaid programs. The accuracy of our definition of type 2 diabetes is unknown. It is possible that our population also erroneously included some individuals with type 1 diabetes, although only $8 \%$ of our population are dual-coded with type 1 diabetes. Individuals with type 1 diabetes are also recommended to receive screening diabetic eye examinations, but the guidelines are different from those with type 2 diabetes. ${ }^{4}$ Administrative claims data are not always accurate for clinical diagnoses and examinations since coding practices may vary by healthcare provider. Although we used previously published cohort and outcome definitions, we could be overestimating adherence to eye examinations if dilation was not performed at these office visits. The definition of adherence also varies in the published literature. Recommendations for frequency of eye examinations depend on the severity of retinopathy and presence of diabetic macular edema, but that level of granularity is not reliably captured in the claims data used in this analysis. ${ }^{45}$ Thus, the definitions of adherence used for this study reflect the most general recommendations of examinations every 1-2 years. ${ }^{4}$ Altering the definition of compliance can drastically change associations, but we were able to show robust findings even in sensitivity analyses. ${ }^{9}$ Lastly, knowledge of diabetic retinopathy and visual impairment from eye disease improves adherence to eye examinations, but these ophthalmic-specific characteristics were not measured in this study and could be confounders. $^{24}$

In conclusion, evaluating and addressing multidimensional SDoH are critical components of promoting adherence to diabetic retinopathy examinations and improving health outcomes. Our study confirms the previous finding that having a regular provider impacts adherence to diabetic retinopathy examinations and has identified poor housing conditions as a novel association that warrants further investigation. Future interventions can focus on these important determinants to improve adherence and eliminate health disparities in diabetic retinopathy care. 
Contributors CXC, SLZ, and MLM designed the study, interpreted the data, and prepared the manuscript. YL acquired the data and performed the data analysis and interpreted the data. CXC is the guarantor.

Funding This study was funded by the National Institute on Minority Health and Health Disparities (R01MD011607).

Competing interests None declared.

Patient consent for publication Not required.

Ethics approval The study was approved by the Institutional Review Board of George Washington University (approval \#081728) and adhered to the tenets of the Declaration of Helsinki.

Provenance and peer review Not commissioned; externally peer reviewed.

Data availability statement Data are available upon reasonable request.

Supplemental material This content has been supplied by the author(s). It has not been vetted by BMJ Publishing Group Limited (BMJ) and may not have been peer-reviewed. Any opinions or recommendations discussed are solely those of the author(s) and are not endorsed by BMJ. BMJ disclaims all liability and responsibility arising from any reliance placed on the content. Where the content includes any translated material, BMJ does not warrant the accuracy and reliability of the translations (including but not limited to local regulations, clinical guidelines, terminology, drug names and drug dosages), and is not responsible for any error and/or omissions arising from translation and adaptation or otherwise.

Open access This is an open access article distributed in accordance with the Creative Commons Attribution Non Commercial (CC BY-NC 4.0) license, which permits others to distribute, remix, adapt, build upon this work non-commercially, and license their derivative works on different terms, provided the original work is properly cited, appropriate credit is given, any changes made indicated, and the use is non-commercial. See: http://creativecommons.org/licenses/by-nc/4.0/.

ORCID iD

Cindy X Cai http://orcid.org/0000-0003-3752-7239

\section{REFERENCES}

1 Centers for Disease Control and Prevention (CDC). National diabetes statistics report 2020. Estimates of diabetes and its burden in the United States. Available: https://www.cdc.gov/diabetes/pdfs/data/ statistics/national-diabetes-statistics-report.pdf [Accessed $11 \mathrm{Feb}$ 2020].

2 Cheung N, Mitchell P, Wong TY. Diabetic retinopathy. Lancet 2010;376:124-36.

3 Saaddine JB, Honeycutt AA, Narayan KMV, et al. Projection of diabetic retinopathy and other major eye diseases among people with diabetes mellitus: United States, 2005-2050. Arch Ophthalmol 2008;126:1740-7

4 Solomon SD, Chew E, Duh EJ, et al. Diabetic retinopathy: a position statement by the American diabetes association. Diabetes Care 2017:40:412-8.

5 Ferris FL. Results of 20 years of research on the treatment of diabetic retinopathy. Prev Med 1994;23:740-2.

6 Sloan FA, Yashkin AP, Chen Y. Gaps in receipt of regular eye examinations among medicare beneficiaries diagnosed with diabetes or chronic eye diseases. Ophthalmology 2014;121:2452-60.

7 Lee PP, Feldman ZW, Ostermann J, et al. Longitudinal rates of annual eye examinations of persons with diabetes and chronic eye diseases. Ophthalmology 2003;110:1952-9.

8 Benoit SR, Swenor B, Geiss LS, et al. Eye care utilization among insured people with diabetes in the U.S., 2010-2014. Diabetes Care 2019;42:427-33.

9 Sloan FA, Brown DS, Carlisle ES, et al. Monitoring visual status: why patients do or do not comply with practice guidelines. Health Serv Res 2004;39:1429-48.

10 Yusuf R, Chen EM, Nwanyanwu K, et al. Neighborhood deprivation and adherence to initial diabetic retinopathy screening. Ophthalmol Retina 2020;4:550-2.

11 Murchison AP, Hark L, Pizzi LT, et al. Non-adherence to eye care in people with diabetes. BMJ Open Diabetes Res Care 2017;5:e000333-10.

12 World Health Organization. A conceptual framework for action on the social determinants of health, 2010. Available: https://www.who. int/sdhconference/resources/ConceptualframeworkforactiononSDH eng.pdf [Accessed 01 May 2021].
13 Hill-Briggs F, Adler NE, Berkowitz SA, et al. Social determinants of health and diabetes: a scientific review. Diabetes Care 2020;44:258-79.

14 Walker RJ, Gebregziabher M, Martin-Harris B, et al. Relationship between social determinants of health and processes and outcomes in adults with type 2 diabetes: validation of a conceptual framework. BMC Endocr Disord 2014;14:S14-10.

15 Silverberg EL, Sterling TW, Williams TH, et al. The association between social determinants of health and self-reported diabetic retinopathy: an exploratory analysis. Int $J$ Environ Res Public Health 2021;18:792.

16 Gibson DM. Eye care availability and access among individuals with diabetes, diabetic retinopathy, or age-related macular degeneration. JAMA Ophthalmol 2014;132:471-7.

17 Lee DJ, Kumar N, Feuer WJ, et al. Dilated eye examination screening guideline compliance among patients with diabetes without a diabetic retinopathy diagnosis: the role of geographic access. BMJ Open Diabetes Res Care 2014;2:e000031.

18 Vijayaraghavan M, Jacobs EA, Seligman $\mathrm{H}$, et al. The association between housing instability, food insecurity, and diabetes selfefficacy in low-income adults. $J$ Health Care Poor Underserved 2011;22:1279-91.

19 Thomson H, Thomas S, Sellstrom E, et al. Housing improvements for health and associated socio-economic outcomes. Cochrane Database Syst Rev 2013;2:CD008657.

20 McCarthy ML, Zheng Z, Wilder ME, et al. Latent class analysis to represent social determinant of health risk groups in the Medicaid cohort of the district of Columbia. Med Care 2021;59:251-8.

21 Flaxel CJ, Adelman RA, Bailey ST, et al. Diabetic retinopathy preferred practice pattern ${ }^{\circledR}$. Ophthalmology 2020;127:P66-145.

22 Kronick R, Gilmer T, Dreyfus T, et al. Improving health-based payment for medicaid beneficiaries: CDPS. Health Care Financ Rev 2000;21:29-64.

23 Glasheen WP, Renda A, Dong Y. Diabetes complications severity index (DCSI)-update and ICD-10 translation. J Diabetes Complications 2017;31:1007-13.

24 Chou C-F, Sherrod CE, Zhang X, et al. Barriers to eye care among people aged 40 years and older with diagnosed diabetes, 20062010. Diabetes Care 2014:37:180-8.

25 An J, Niu F, Turpcu A, et al. Adherence to the American diabetes association retinal screening guidelines for population with diabetes in the United States. Ophthalmic Epidemiol 2018;25:257-65.

26 Paksin-Hall A, Dent ML, Dong F, et al. Factors contributing to diabetes patients not receiving annual dilated eye examinations. Ophthalmic Epidemiol 2013;20:281-7.

27 Keenum Z, McGwin G, Witherspoon CD, et al. Patients' adherence to recommended follow-up eye care after diabetic retinopathy screening in a publicly funded county clinic and factors associated with follow-up eye care use. JAMA Ophthalmol 2016;134:1221.

$28 \mathrm{Paz} \mathrm{SH}$, Varma R, Klein R, et al. Noncompliance with vision care guidelines in latinos with type 2 diabetes mellitus: the Los Angeles Latino eye study. Ophthalmology 2006;113:1372-7.

29 Healthy People 2030. Increase the proportion of adults with diabetes who have a yearly eye exam, 2030. Available: https://health.gov/ healthypeople/objectives-and-data/browse-objectives/diabetes/ increase-proportion-adults-diabetes-who-have-yearly-eye-exam-d04 [Accessed 25 Mar 2021].

30 Healthy People. Available: https://www.cdc.gov/nchs/healthy people/index.htm [Accessed 18 Aug 2021].

31 Kirkman MS, Williams SR, Caffrey HH, et al. Impact of a program to improve adherence to diabetes guidelines by primary care physicians. Diabetes Care 2002;25:1946-51.

32 Holley CD, Lee PP. Primary care provider views of the current referral-to-eye-care process: focus group results. Invest Ophthalmol Vis Sci 2010;51:1866-72.

33 Storey PP, Murchison AP, Pizzi LT, et al. Impact of physician communication on diabetic eye examination adherence. Retina 2016;36:20-7.

34 Berkowitz SA, Seligman HK, Choudhry NK. Treat or eat: food insecurity, cost-related medication underuse, and unmet needs. Am J Med 2014;127:303-10.

35 Amuda AT, Berkowitz SA. Diabetes and the built environment: evidence and policies. Curr Diab Rep 2019;19:35.

36 Carcone Al, Ellis DA, Naar-King S. Linking caregiver strain to diabetes illness management and health outcomes in a sample of adolescents in chronically poor metabolic control. J Dev Behav Pediatr 2012;33:343-51.

37 Eppley SE, Mansberger SL, Ramanathan S, et al. Characteristics associated with adherence to annual dilated eye examinations among US patients with diagnosed diabetes. Ophthalmology 2019:126:1492-9. 
38 Obeid A, Gao X, Ali FS, et al. Loss to follow-up in patients with proliferative diabetic retinopathy after Panretinal photocoagulation or intravitreal anti-VEGF injections. Ophthalmology

2018;125:1386-92.

39 Nitkin K. A new way to document social determinants of health, 2011. Available: https://www.hopkinsmedicine.org/office-of-johnshopkins-physicians/best-practice-news/a-new-way-to-documentsocial-determinants-of-health [Accessed 25 Mar 2021].

40 Gold R, Bunce A, Cowburn S, et al. Adoption of social determinants of health EHR tools by community health centers. Ann Fam Med 2018;16:399-407.

41 Health Leads. Health leads social needs screening toolkit. Available: https://healthleadsusa.org/resources/the-health-leads-screeningtoolkit/ [Accessed 25 Mar 2021].
42 Institute of Medicine. Capturing social and behavioral domains in electronic health records: phase 1. Washington, DC: The National Academies Press, 2014.

43 Healthy People 2030. Social determinants of health. Available: https://health.gov/healthypeople/objectives-and-data/socialdeterminants-health [Accessed 25 Mar 2021].

44 University of Wisconsin Population Health Institute. County health rankings model. Available: https://www.countyhealthrankings.org/ explore-health-rankings/measures-data-sources/2020-measures [Accessed 25 Mar 2021].

45 Cai CX, Michalak SM, Stinnett SS, et al. Effect of ICD-9 to ICD-10 transition on accuracy of codes for stage of diabetic retinopathy and related complications: results from the CODER study. Ophthalmol Retina 2021;5:374-80. 